\title{
Intrabiliary resection of metastasis originating from colorectal carcinoma during direct peroral cholangioscopy: a new tool for biliary palliation
}

Intrabiliary growth of a liver metastasis originating from colorectal carcinoma is a rare manifestation of metastatic liver carcinoma, with only a few cases reported in the literature [1-3]. Radiological characteristics of the "classic" liver metastases are well established, and generally preoperative biopsy to plan a proper surgical strategy is not required. However, the radiological features of intrabiliary liver metastasis

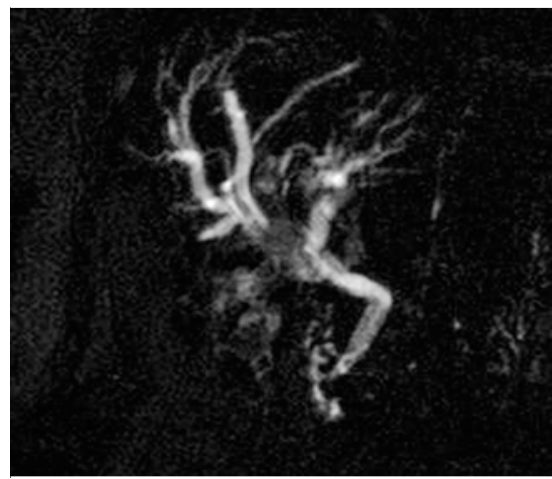

- Fig. 1 Magnetic resonance imaging showed dilation of the intrahepatic biliary ducts and common bile duct, with an intraductal nodule at the hepatic hilum. may not be distinctive, leading to possible misdiagnosis.

We present the case of an 83-year-old woman who was referred to our unit because of jaundice. The medical history reported left hemicolectomy for cancer (pT3N0) 15 years earlier and hepatic segmentectomy for metastatic nodule 5 years earlier. Computed tomography and magnetic resonance imaging scans showed dilation of the common bile duct and intrahepatic bile ducts, with an intraductal nodule at the hepatic hilum (ฉ Fig.1). Carcinoembryonic antigen and $\alpha$-fetoprotein levels were normal. Endoscopic retrograde cholangiopancreatography showed a dilated biliary duct $(14 \mathrm{~mm})$ with a "negative" image of about $20 \mathrm{~mm}$ at the bifurcation.

After sphincterotomy and papilloplasty up to $12 \mathrm{~mm}$, direct peroral cholangioscopy (POC) was performed using a slim scope $(8.5 \mathrm{~mm}$ diameter, EG 530FP; Fujifilm, Tokyo, Japan). A polypoid mass with irregular vascular pattern, highly suggestive of malignancy, was observed at the hepatic hilum ( $\mathbf{F i g . 2}$ a). Endoscopic resection of the lesion, under direct visuali- zation, with a hot snare (15 mm, Captivator II; Boston Scientific Corp., Marlborough, Massachusetts, USA) was performed, thus avoiding the need for biliary stent placement ( $\triangleright$ Fig. $\mathbf{2} \mathbf{b}, \triangleright$ Video $\mathbf{1}$ ). Histology revealed a metastasis of colorectal carcinoma (\$Fig.3). The patient remained free of symptoms with normal bilirubin level for 12 months.

To our knowledge this is the first case of an intrabiliary endoscopic resection performed under direct visualization. The $P O C$ is an advanced technique for intraluminal visual inspection and for therapeutic intervention of the biliary ducts [4], and shows potential as a promising approach in the diagnosis and treatment of a subgroup of patients with biliary obstruction secondary to intraductal masses.

Endoscopy_UCTN_Code_TTT_1AR_2AF

\section{Competing interests}

Andrea Anderloni is a consultant for Boston Scientific.
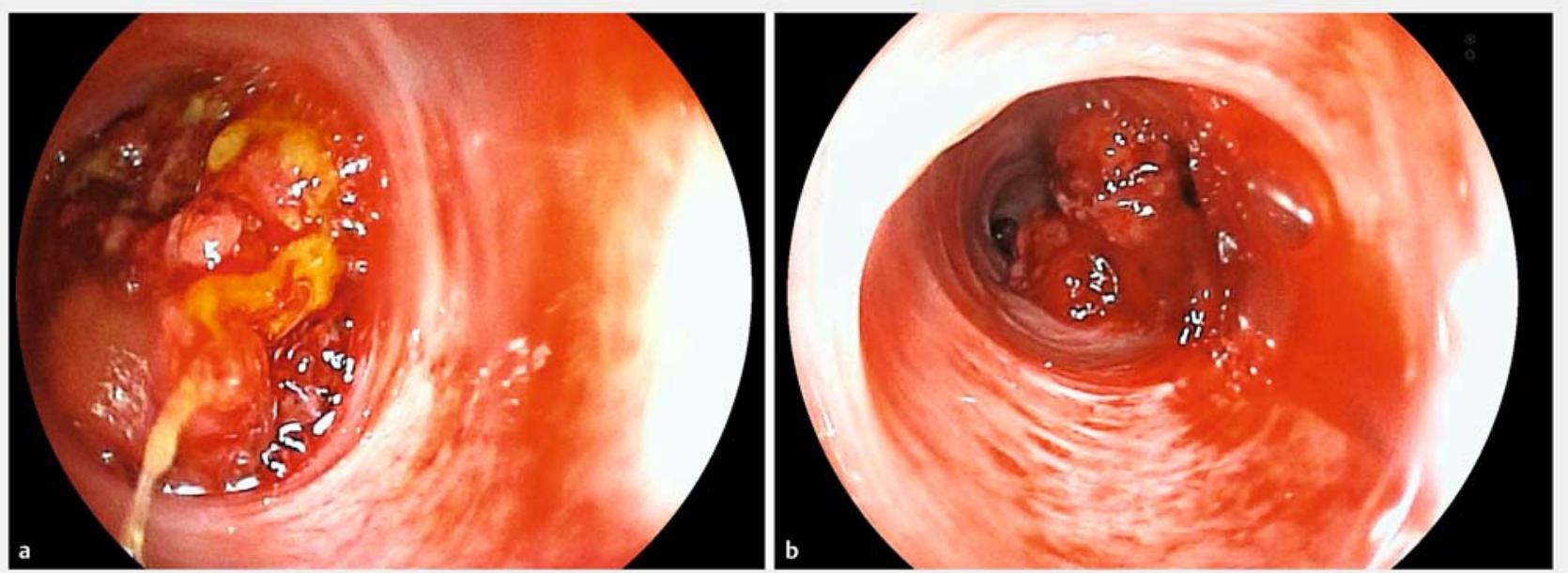

- Fig. 2 Direct peroral cholangioscopy. a Visualization of an obstructive polypoid mass, with irregular vascular pattern and surface at the hepatic hilum. b Evaluation after resection showed no more obstruction of the hilum and visualization of the intrahepatic biliary ducts. 


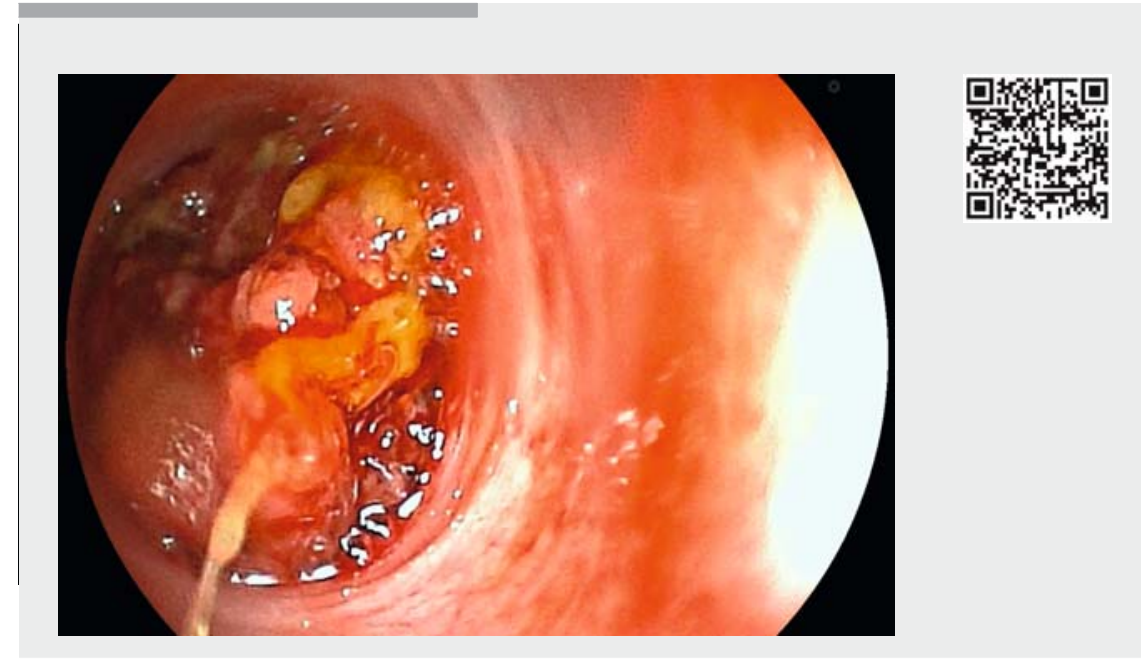

$\checkmark$ Video 1 Filling defect at cholangiography. Sphincterotomy and papilloplasty up to $12 \mathrm{~mm}$. Direct peroral cholangioscopy (POC) performed using a slim endoscope $(8.5 \mathrm{~mm}$ diameter, EG 530FP; Fujifilm, Tokyo, Japan) showed an obstructive polypoid mass with irregular vascular pattern (FICE, Fujifilm). Endoscopic resection of the lesion was performed using a hot snare.

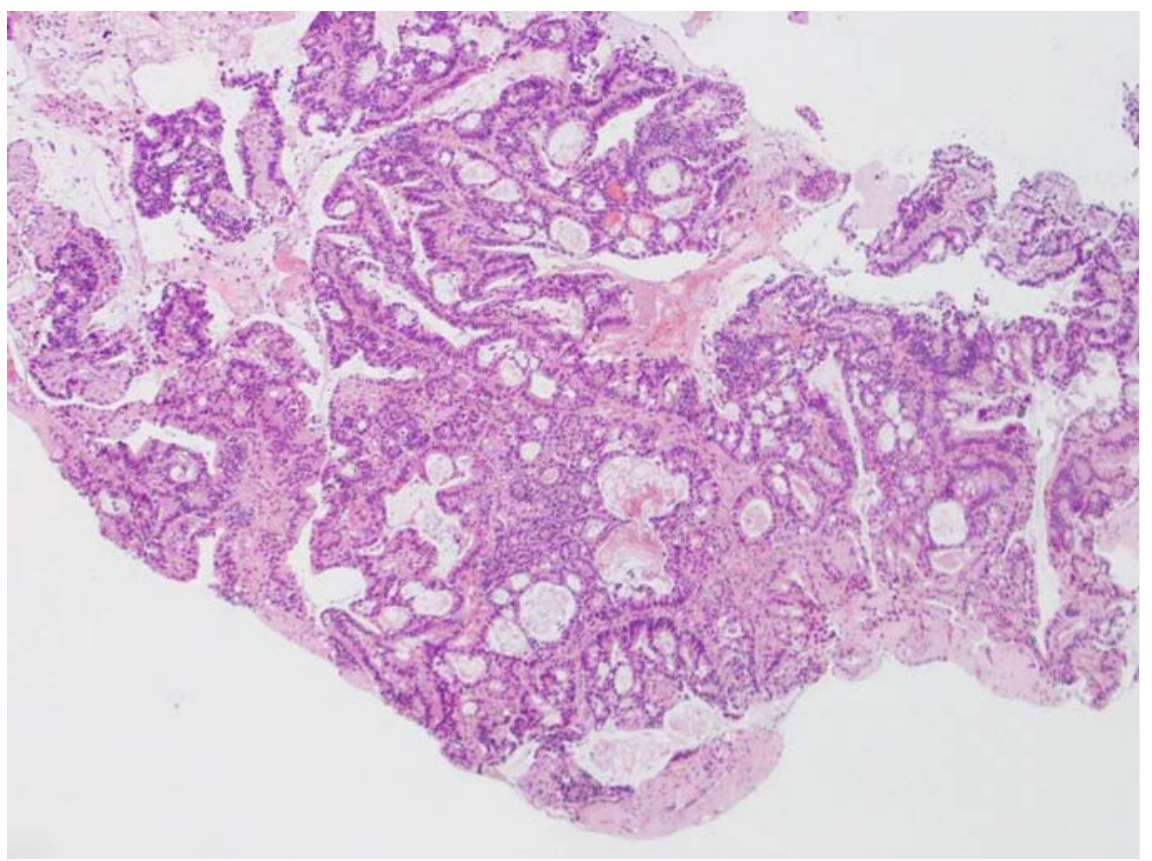

- Fig. 3 Histology revealed metastasis of colorectal carcinoma (hematoxylin and eosin).

\section{References}

[1] Estrella JS, Othman ML, Taggart MW et al. Intrabiliary growth of liver metastases clinicopathologic features, prevalence, and outcome. Am J Surg Pathol 2013; 37: 1571 1579

[2] Dong Y, Patel H, Patel C. Intrabiliary hepatic metastasis of colorectal carcinoma mimicking primary cholangiocarcinoma: a case report and review of the literature. Case Rep Pathol 2016; 2016: 4704781

[3] Conci S, De Bellis M, Ruzzenente A et al. Totally intrabiliary colorectal liver metastasis mimicking intraductal growth-type cholangiocarcinoma. Updates Surg 2016; 68: 211-212

[4] Meves V, Ell C, Pohl J. Efficacy and safety of direct transnasal cholangioscopy with standard ultraslim endoscopes: results of a large cohort study. Gastrointest Endosc 2014; 79: 88-94

\section{Bibliography}

DOI https://doi.org/10.1055/s-0044-100487

Published online: 2.2.2018

Endoscopy 2018; 50: E97-E98

(c) Georg Thieme Verlag KG

Stuttgart · New York

ISSN 0013-726X

\section{ENDOSCOPY E-VIDEOS}

https://eref.thieme.de/e-videos

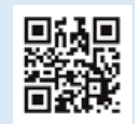

Endoscopy E-Videos is a free access online section, reporting on interesting cases and new techniques in gastroenterological endoscopy. All papers include a high quality video and all contributions are freely accessible online.

This section has its own submission website at

https://mc.manuscriptcentral.com/e-videos
The authors

Andrea Anderloni ${ }^{1}$, Alessandro Fugazza ${ }^{1}$, Francesco Auriemma ${ }^{1}$, Roberta Maselli ${ }^{1}$, Ferdinando D'Amico', Edoardo Troncone' ${ }^{1}$, Alessandro Repici ${ }^{1,2}$

1 Digestive Endoscopy Unit, Division of Gastroenterology, Humanitas Research Hospital, Rozzano, Milan, Italy

2 Humanitas University, Rozzano, Milan, Italy
Corresponding author

\section{Andrea Anderloni, MD, PhD}

Digestive Endoscopy Unit, Division of

Gastroenterology, Humanitas Research

Hospital, Via Manzoni 56, 20089 Rozzano

(Milano), Italy

Phone: +39-02-82247308

andrea.anderloni@humanitas.it 